\title{
EDITORIAL CORRECTION
}

In Culture, Medicine and Psychiatry 4 (1), on page 17, there was an unfortunate error in the subtitle of Dr Derson Young's paper on 'The Relationship between Etiology and Symptomatology in Psychiatry'. Regrettably, the name of the Hunan Medical College, where Dr Young is Associate Professor, has been misprinted. The subtitle should read: "A Lecture for Postgraduate Students in the Department of Psychiatry, Hunan Medical College, People's Republic of China". The Editor-in-Chief apologizes for this mistake. 